\title{
Proteomic analysis of Red Sea Conus taeniatus venom reveals potential biological applications
}

\author{
Maged M. A. Fouda ${ }^{1,2}$, Mohammed Abdel-Wahab ${ }^{2}$, Amal Mohammadien, ${ }^{3,4}$, Mousa O. Germoush ${ }^{1}$, \\ Moustafa Sarhan ${ }^{2 *}$ (1) \\ ${ }^{1}$ Department of Biology, College of Science, Jouf University, Saudi Arabia. \\ ${ }^{2}$ Zoology Department, Faculty of Science, Al-Azhar University, Assiut, Egypt. \\ ${ }^{3}$ Department of Biology, College of Science, Taeif University, Saudi Arabia. \\ ${ }^{4}$ Zoology Department, Faculty of Science, Zagazig University, Zagazig, Egypt.
}

\section{Keywords:}

Conus taeniatus

Conopeptides

Conotoxin

HPLC

Mass spectrometry

Cone snail venom

\begin{abstract}
Background: Diverse and unique bioactive neurotoxins known as conopeptides or conotoxins are produced by venomous marine cone snails. Currently, these small and stable molecules are of great importance as research tools and platforms for discovering new drugs and therapeutics. Therefore, the characterization of Conus venom is of great significance, especially for poorly studied species.

Methods: In this study, we used bioanalytical techniques to determine the venom profile and emphasize the functional composition of conopeptides in Conus taeniatus, a neglected worm-hunting cone snail.

Results: The proteomic analysis revealed that $84.0 \%$ of the venom proteins were between 500 and 4,000 Da, and $16.0 \%$ were $>4,000 \mathrm{Da}$. In C. taeniatus venom, 234 peptide fragments were identified and classified as conotoxin precursors or non-conotoxin proteins. In this process, 153 conotoxin precursors were identified and matched to 23 conotoxin precursors and hormone superfamilies. Notably, the four conotoxin superfamilies T (22.87\%), O1 (17.65\%), M (13.1\%) and O2 (9.8\%) were the most abundant peptides in C. taeniatus venom, accounting for $63.40 \%$ of the total conotoxin diversity. On the other hand, 48 non-conotoxin proteins were identified in the venom of $C$. taeniatus. Moreover, several possibly biologically active peptide matches were identified, and putative applications of the peptides were assigned.

Conclusion: Our study showed that the composition of the C. taeniatus-derived proteome is comparable to that of other Conus species and contains an effective mix of toxins, ionic channel inhibitors and antimicrobials. Additionally, it provides a guidepost for identifying novel conopeptides from the venom of $C$. taeniatus and discovering conopeptides of potential pharmaceutical importance.
\end{abstract}

* Correspondence: msarhan@azhar.edu.eg https://doi.org/10.1590/1678-9199-JVATITD-2021-0023

Received: 04 March 2021; Accepted: 12 May 2021; Published online: 18 October 2021 


\section{Background}

Cone snails are venomous marine mollusks of the genus Conus that can produce small cysteine-rich peptides called conotoxins or conopeptides. These conopeptides display diverse pharmacological activities for prey capture, self-defense, competition, and other biological purposes [1,2]. According to their prey preference, cone snails are commonly classified into three main groups: vermivore, molluscivore or piscivore $[3,4]$. Conopeptides can modulate the nervous system of their targets by affecting ion channels [5-7]. Therefore, conopeptides have become a platform for discovering new drugs in these exceptionally potent venoms. Moreover, specific components in Conus venoms are used as therapeutics. For example, $\omega$-MVIIA conotoxin is known commercially as ziconotide (Prialt ${ }^{\circ}$ ) and is utilized to cure chronic pain [8-12]. Several other conopeptides are being studied for the treatment of neuropathic pain, epilepsy, hypertension and myocardial infarction [13]. In addition to their contribution to neurobiological and therapeutic applications, conotoxins show high diversity. Conopeptides are stable, relatively small, and structurally diverse with various cysteine frameworks and numerous posttranslational modifications (PTMs) [14-16]. To date, over 800 species of cone snails have been described [17]. Assuming that the venom of each species contains 100 distinct peptides, a repertoire of more than 80,000 conopeptides could be obtained. However, currently only a restricted number of conopeptides $(\sim 3 \%)$ have been characterized $[18,19]$. Conopeptides are generated from mRNA-encoded conopeptide precursors that possess signal peptides followed by a variable region and a hypervariable mature peptide $[20,21]$. At present, conotoxins are classified based on three classification methods: (1) peptide precursor identity, (2) cysteine frameworks, and (3) pharmacological targets and activity. Thus far, twelve families of conotoxins have been identified [18,22].

The worm-hunting cone snail C. taeniatus is commonly distributed along the Egyptian Red Sea. However, there is no information regarding its venom composition. Thus, a proteomic analysis of $C$. taeniatus venom is of great interest and essential to uncover its various components. In the present study, highperformance liquid chromatography (HPLC) fractionation combined with LC/mass spectrometry (LC-MS) and offline matrix-assisted laser desorption/ionization (MALDI)-time-offlight (TOF)-MS was used to assess the conopeptide content in the venom of $C$. taeniatus. This integrated approach provides an initial outline of $C$. taeniatus venom constituents and presents information about potential bioactive peptide candidates that may have pharmaceutical importance. To our knowledge, this is the first proteomic analysis of the venom of Red Sea endemic Conus species, and therefore, it provides information that complements and enriches the field of cone toxinology.

\section{Methods}

\section{Crude venom extraction}

Specimens of C. taeniatus $(n=40)$ were collected from several sites along the Red Sea coast of Egypt (Figure 1A and 1B). After carefully dissecting the snail venom apparatus, the venom ducts were sliced into small parts to extract the protein contents. For extraction, parts of the venom ducts were suspended in two percent acetic acid (AA) and then centrifuged at $500 \times \mathrm{g}$ for 5 minutes at $4^{\circ} \mathrm{C}$. The venom was extracted three times, freezedried, and then saved at $-80^{\circ} \mathrm{C}$ until use.

\section{LC/MS analysis}

LC/MS measurements of $C$. taeniatus venom were analyzed using an electrospray ion source (ESI) equipped with an LCMSIT-TOF (Shimadzu). A reversed-phase C18 HPLC (RP-HPLC) column (Cadenza CD-C18, $2.0150 \mathrm{~mm}$; Imtakt) was used for separation. The column was eluted with $0.1 \%$ formic acid (FA) in $\mathrm{H}_{2} \mathrm{O}$ (solvent $\mathrm{A}$ ) and $0.1 \%$ formic acid in $\mathrm{CH} 3 \mathrm{CN}$ (solvent $\mathrm{B}$ ) at a flow rate of $0.2 \mathrm{~mL} / \mathrm{min}$ with a linear gradient of $5 \%-60 \%$ solvent $\mathrm{B}$ in solvent $\mathrm{A}$, over 55 minutes.

\section{Reduction and carboxyamidomethylation of the venom}

The reduction of crude venom $(100 \mu \mathrm{g})$ was performed in a buffer containing $0.13 \mathrm{M} \mathrm{NaHCO} 3$ ( $\mathrm{pH} 8.5$ ), 2.7 M urea, and 35 $\mathrm{mM}$ dithiothreitol (DTT), and then the mixture was incubated at $50^{\circ} \mathrm{C}$ for one hour under argon gas. The combined reaction mixture was then mixed with iodoacetamide (IAA) at a final concentration of $125 \mathrm{mM}$ and incubated for $1 \mathrm{~h}$ at $25^{\circ} \mathrm{C}$ for the alkylation process. The final mixture including the derivatized peptides was analyzed by LC/MS without purification.

\section{MALDI-TOF/MS analysis}

MALDI-TOF-TOF/MS analysis was performed on a TripleTOF ${ }^{\mathrm{m}}$ $5600+$ (AB Sciex, Canada). The venom samples were first desalted by using MonoSpin reversed-phase C18 columns (GlSciences, Cat. No. 5010-21701) prior to the measurement. The venom was dissolved in a matrix solution containing a-cyano-4-hydroxycinnamic acid (HCCA, $2.5 \mathrm{mg}$, Bruker Daltonics), dissolved in $\mathrm{CH} 3 \mathrm{CN}$ (50\%, $0.1 \%$ formic acid, Sigma-Aldrich). One $\mu l$ of the solution was spotted onto a target plate (Bruker Daltonics) and allowed to dry at room temperature. For high precision, external calibration of the sample batches was carried out to correct possible TOF deviation. Measurements were conducted in positive ion mode, and the MS and MS/MS ranges were $400-1250$ and $170-1500 \mathrm{~m} / \mathrm{z}$, respectively. Mass spectra raw files from the TripleTOF ${ }^{\mathrm{TM}} 5600+$ were converted into Mascot 
A

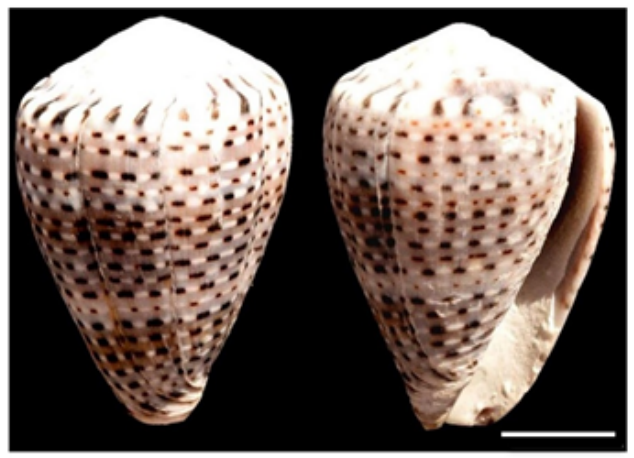

B

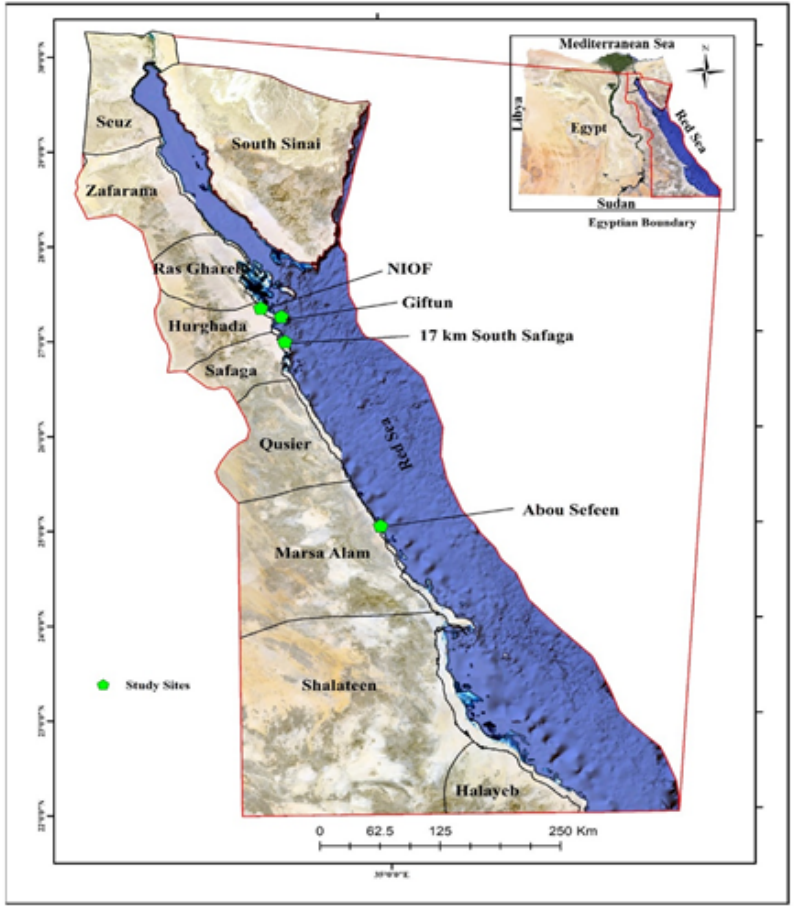

Figure 1. (A) General morphology of $C$. taeniatus shell $(\mathrm{bar}=1 \mathrm{~cm})$ and $\mathbf{( B )}$ map of the Red Sea in Egypt showing the collection sites of $C$. taeniatus.

generic format (mgf) files using the script provided by AB Sciex and ProteoWizard. The MS/MS spectra were searched using $\mathrm{X}$ ! Tandem in a Peptide-shaker (v1.16.38) against the UniProt Conus organism (Swiss-Prot and TrEMBL containing 10684 proteins) with reversed sequences. With initial mass tolerances of 20.0 and $10.0 \mathrm{ppm}$, the precursor and fragment masses were established, respectively. The carbamidomethylation of cysteine (mass $57.02 \mathrm{amu}$ ) was considered to be a static modification, and the oxidation at methionine (mass $15.99 \mathrm{amu}$ ), acetylation of the protein N-terminus (mass $42.01 \mathrm{amu}$ ), deamidation of asparagine (mass $0.98 \mathrm{amu}$ ), and deamidation of glutamine (mass $0.98 \mathrm{amu}$ ) were considered to be variable modifications. Subsequently, the UniProtKB database (www.uniprot.org) and the Entrez PubMed database (www.ncbi.nih.gov) were used to determine the gene superfamilies found in the crude venom of C. taeniatus from known protein fragments.

\section{Results}

\section{Molecular mass range and distribution of conopeptides detected by LC/MS}

To study the total number of peptide profiles produced in the venom of C. taeniatus, an online LC/MS equipped with an ESI source (LCMS-IT-TOF; Shimadzu) was used to analyze quantified crude venom samples. The LC/MS spectra of the extracted crude venom from $C$. taeniatus demonstrate the remarkable complexity of conopeptides present in this species (Figure 2A and 2B). The LC/MS analysis revealed approximately 149 components from C. taeniatus venom. Those between 500 and 4,000 Da represented $84 \%$ of the conopeptides, and the large peptides $(>4,000 \mathrm{Da})$ constituted only $16 \%$ of all C. taeniatus components (Figure 3, Additional file 1). The molecular mass 
A
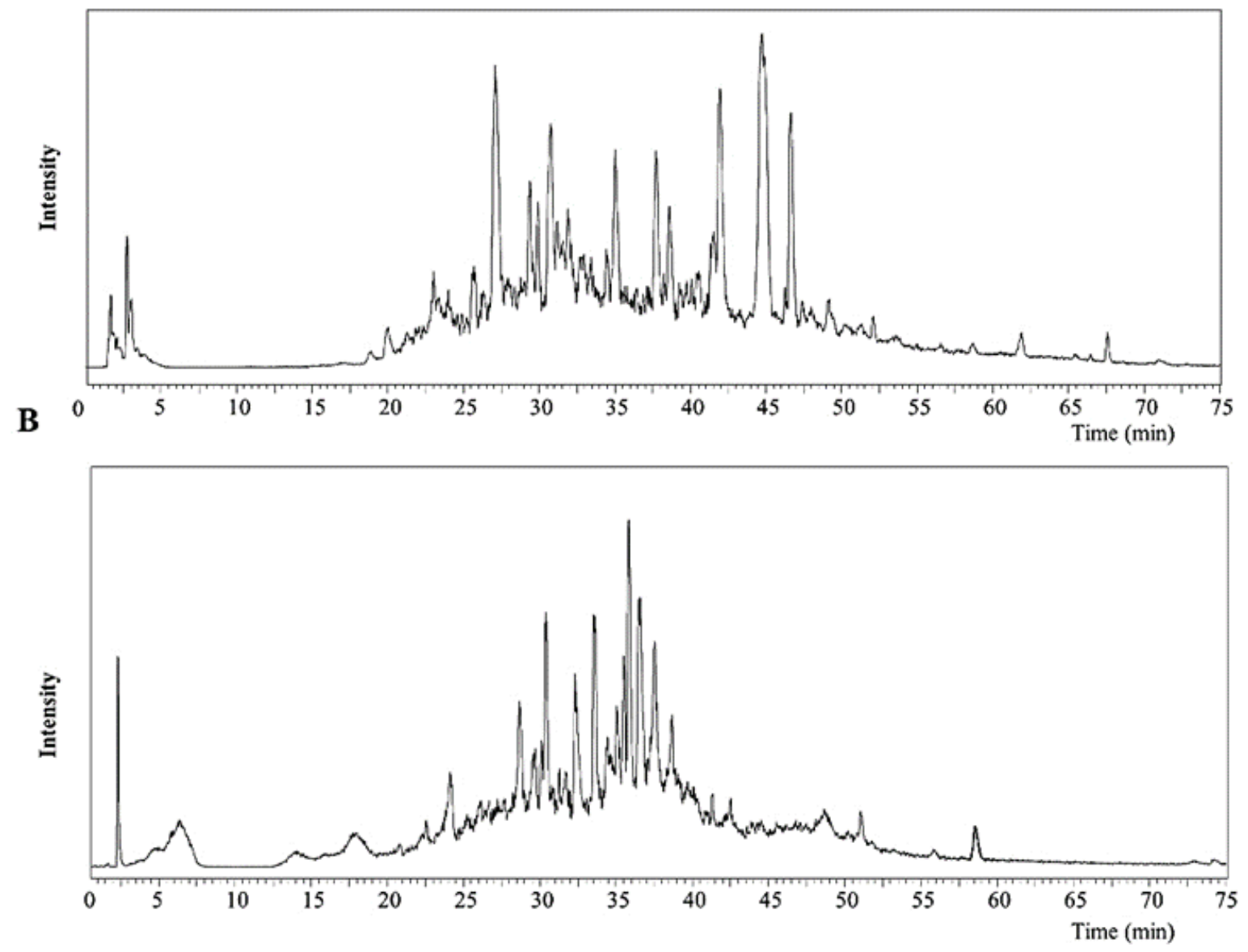

Figure 2. LC/MS chromatograms of (A) native and (B) Cys-alkylated C. taeniatus venom.

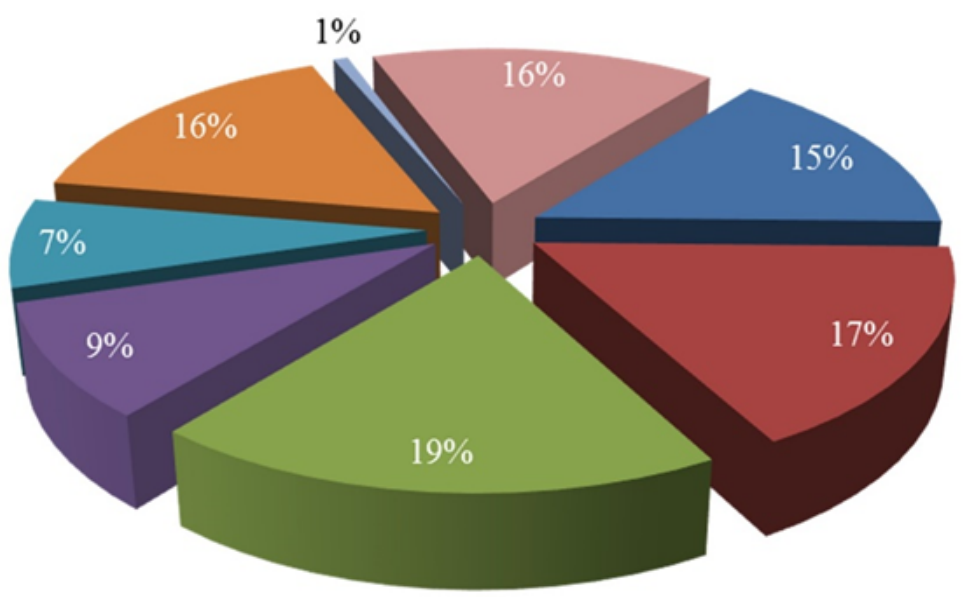

\begin{tabular}{|c|c|c|}
\hline = 500-1000 & - 1001-1500 & = 1501-2000 \\
\hline 2501-3000 & -3001-3500 & -3501-4000 \\
\hline
\end{tabular}

\section{Mass range (Da)}

Figure 3. Molecular mass distribution of the components in C. taeniatus venom detected by LC/MS. 
distribution of the components in C. taeniatus venom in relation to their total ion current intensity showed a bimodal distribution. The molecular mass can be observed with one major mode (500-3,000 Da) and one minor mode (3,000-7,000 Da). These results clearly show that $C$. taeniatus peptides between 1,000 and 2,000 Da are highly represented compared with those of other molecular masses.

\section{Conopeptides with disulfide bridges and cysteine distribution}

LC/MS analysis of the DTT-reduced venom component derivatives of $C$. taeniatus demonstrated an increase in molecular mass by $116.058 \times n$ Da. Disulfide bond-containing components were detected in C. taeniatus venom (Additional file 2). Forty disulfide bond-containing components were confirmed and the cysteine distribution of those conopeptides is shown in Figure $4 \mathrm{~A}$ and Additional file 3 . The number of disulfide bonds ranged from one to five, and the 0-, 2-, and 3-disulfide frameworks were common in the $C$. taeniatus conopeptides. Peptides contained a 6-cysteine framework, which represents three disulfide bridges, were the most common in the venom. Conopeptides were also divided into "disulfide-poor" (containing two or no cysteines) and "disulfide-rich" (containing four to ten cysteines) groups. The results revealed that $68.75 \%$ of the identified peptides were disulfide-rich and the remaining $31.25 \%$ were mostly disulfidepoor (Figure 4B and Additional file 3).

\section{Conotoxin diversity of $C$. taeniatus with respect to superfamily}

A total of 290 peptide fragments (Additional file 4) were detected in the venom of $C$. taeniatus. A protein sequence similarity search in the database revealed that 170 peptides belonging to 153 conotoxin proteins were assigned to 23 conopeptide superfamilies: the $\mathrm{A}, \mathrm{B} 1$, B2, E, F, H, I1, I2, M, O1, O2, O3, P, S, T, V, Conkunitzin, Conikot-ikot, Conodopin, Cerm, Pmag and two hormone families (Conopressin/Conophysin and prohormone-4). The sequences of these peptides are shown in Table 1. Notably, T, O1, M and O2 constitute the highest percentages $(22.87 \%, 17.56 \%, 13.1 \%$ and $9.8 \%$, respectively) of the known superfamilies. Furthermore, some rare superfamilies of conotoxins were found in the venom of $C$. taeniatus. Only one peptide fragment sequence was detected from each of the following conotoxin superfamilies: $\mathrm{E}, \mathrm{H}$, Conikot-ikot, Pmag and Prohormone-4 (Figure 5). Additionally, 48 non-conotoxin proteins were identified including conoporin, protein disulfide isomerase, arginine kinase and Kazal proteinase inhibitor (Table 2).

The relative abundance of conopeptide superfamilies in $C$. taeniatus venom is expressed as the percent relative abundance of total identified proteins by LC-MS/MS.

\section{Discussion}

The venom components of marine cone snails have evolved bioactive peptides targeting various biological activities to quickly paralyze their preferred prey. Studies have focused on both fish- and mollusk-hunting cone snail venoms because of the biomedical interest of their conopeptides [23]. Information on the peptide profile of worm-hunting species remains limited, despite their significance as a source of pharmacological compounds [24-26]. Thus, vermivore snails might also be promising pharmacological sources $[27,28]$.

It is technically difficult to determine the precise number of components in the venom using biological activity methods [29]. In contrast, LC/MS supplied with an ESI source (LCMSIT-TOF) is an effective way to provide an abundance of valuable data. This approach revealed a high degree of conopeptide diversity and increased the predicted number from 200 to $>1100$ distinct toxins per Conus species. In the present study, we observed diverse components in the venom of C. taeniatus. After mass deconvolution and filtering, a total of more than one hundred different molecular masses were detected from the venom of $C$. taeniatus. Previous studies reported between 50 and 1,000 conopeptides for a Conus species [14,30,31]. This variability may enable C. taeniatus to modify the composition of the injected venom according to the predatory or defensive stimuli. A total of 276, 298 and 488 different molecular masses were identified in C. imperialis, C. fulgetrum and C. crotchii venoms, respectively [14,32]. Furthermore, more than 500 different compounds were detected in the venom of $C$. consors by MALDI-MS alone and more than 700 by ESI-MS [33]. In our proteomic study, LCMS-IT-TOF and MS/MS were used to discover the peptide profile and predict putative conotoxin gene superfamilies in the neglected worm-hunting snail C. taeniatus. The number of distinct peptides previously reported in different species varies considerably. For example, 290 peptides were detected in C. taeniatus venom (this study), 1,746 peptides in the venom of C. textile [14], and 8,000 peptides in the venom of C. marmoreus [34]. Significant differences in peptide numbers in the proteomic analysis of Conus species may be due to the difference in methods of venom collection, total number of collected specimens and pooled data, or different conditions used for peptide authentication $[35,36]$.

In the present study, we reported that the majority (84\%) of $C$. taeniatus components were $500-4,000 \mathrm{Da}$, whereas only $16 \%$ of all components were large peptides $(>4,000 \mathrm{Da})$. In addition, over $50 \%$ of the conopeptides detected in the venom of the studied species were smaller than 2,500 Da. [37]. Similarly, low molecular weight peptides were the most abundant in C. fulgetrum venom [37], C. marmoreus and C. bandanus venoms [2]. Although these species share worm-like prey, they evolved different strategies to 
$\mathbf{A}$

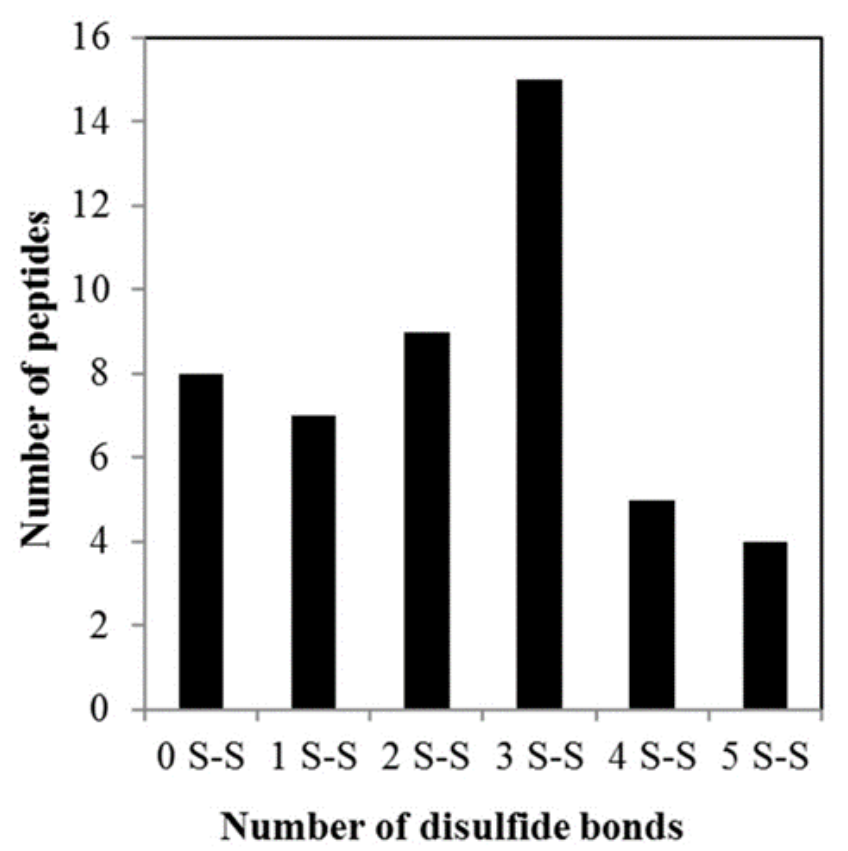

B

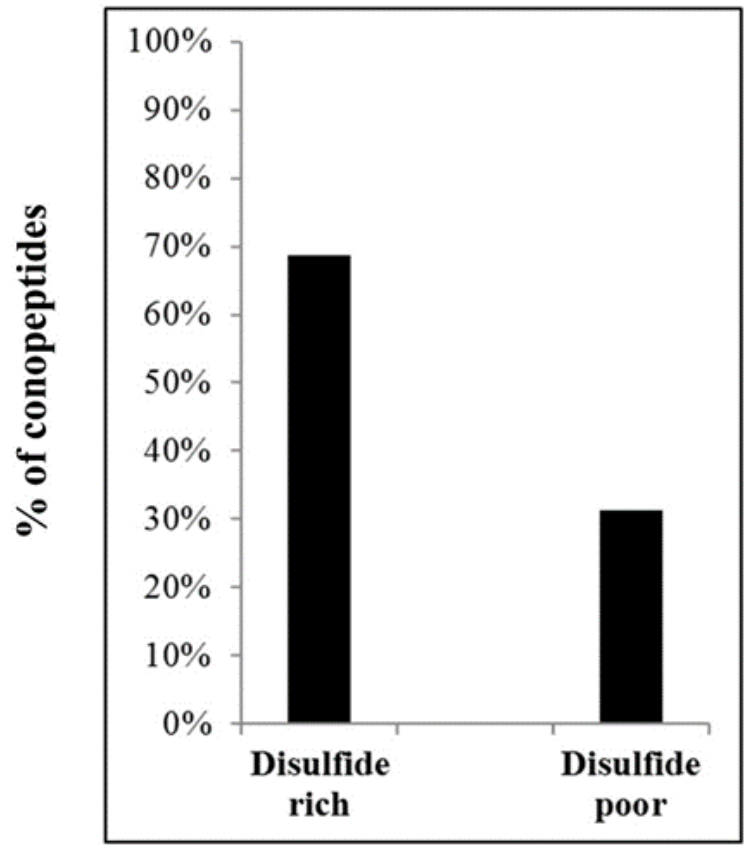

Figure 4. Number of disulfide bridges determined based on the mass shift detected by LC/MS after reduction/alkylation of Cys residues.

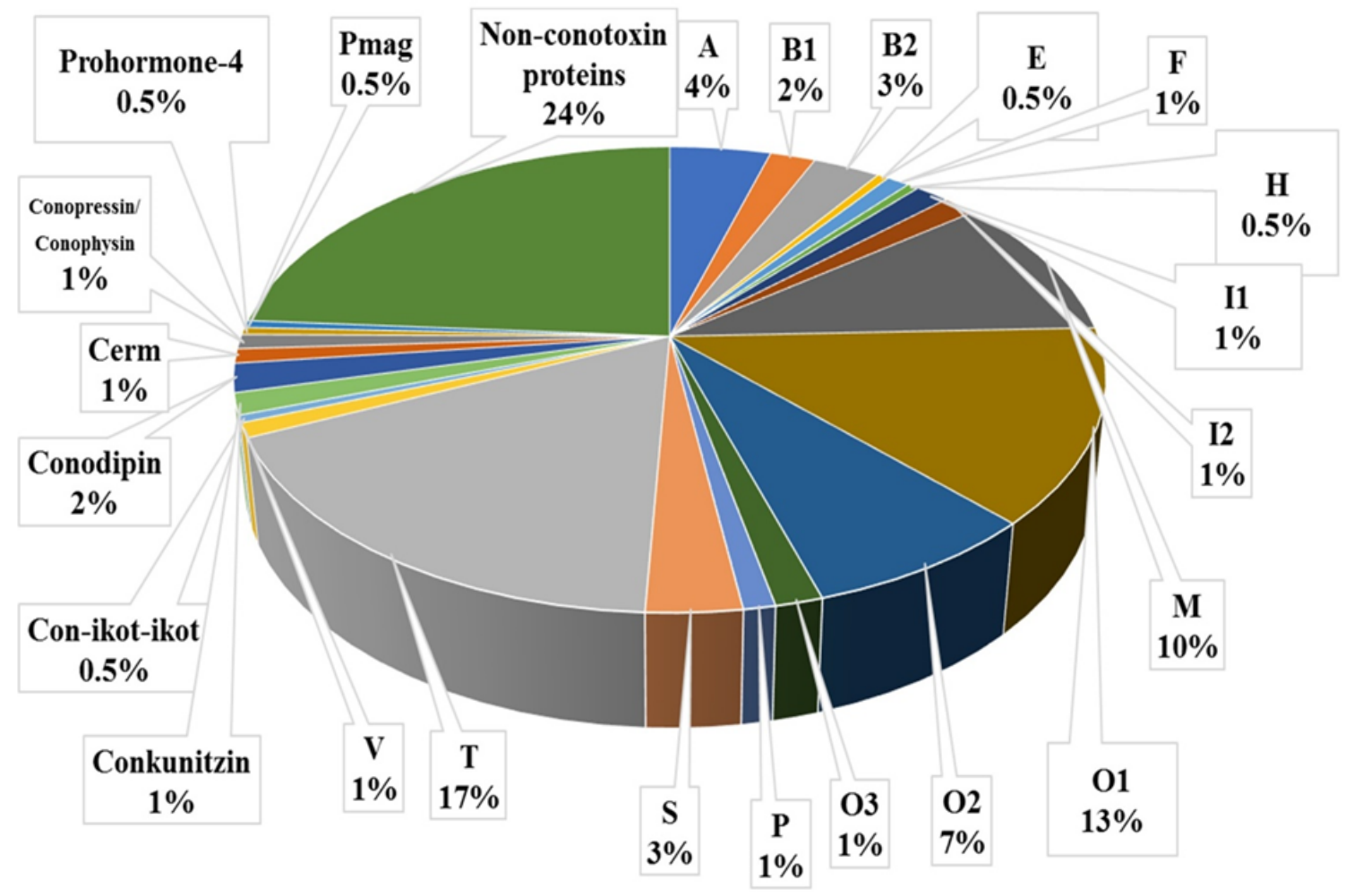

Figure 5. Percentage composition of conotoxin superfamilies and non-conotoxin proteins in C. taeniatus venom proteome. 
Table 1. List of identified conotoxin proteins in the venom of Egyptian C. taeniatus with their corresponding gene superfamilies, type of targets and possible applications.

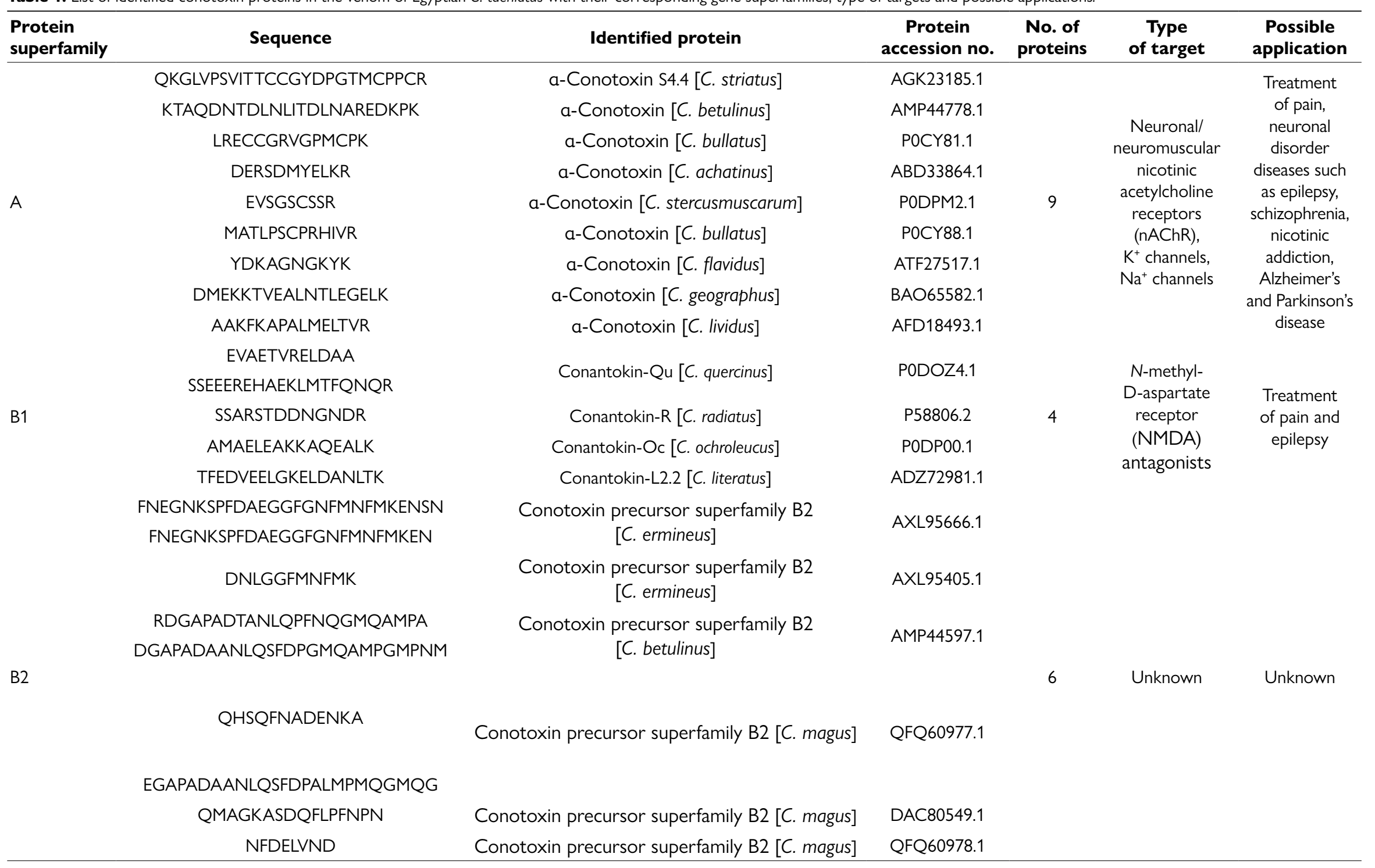


Table 1. Cont.

\begin{tabular}{|c|c|c|c|c|c|c|}
\hline $\begin{array}{l}\text { Protein } \\
\text { superfamily }\end{array}$ & Sequence & Identified protein & $\begin{array}{c}\text { Protein } \\
\text { accession no. }\end{array}$ & $\begin{array}{l}\text { No. of } \\
\text { proteins }\end{array}$ & $\begin{array}{c}\text { Type } \\
\text { of target }\end{array}$ & $\begin{array}{l}\text { Possible } \\
\text { application }\end{array}$ \\
\hline $\mathrm{E}$ & TCVALSSLNECAVREK & $\begin{array}{c}\text { Conotoxin precursor superfamily } \mathrm{E} \\
\text { [C. ermineus] }\end{array}$ & AXL95533.1 & 1 & Unknown & Unknown \\
\hline \multirow{4}{*}{$\mathrm{F}$} & GQKLMHACSIANKYTYD & & & \multirow{4}{*}{2} & \multirow{4}{*}{ Unknown } & \multirow{4}{*}{ Unknown } \\
\hline & LMHACSIANK & Conotoxin precursor superfamily $F$ [C. magus] & QFQ60998.1 & & & \\
\hline & VYHSMMGDMVTCLNHFFRR & & & & & \\
\hline & MNPYSPMNPVNSLYNPMK & Conotoxin precursor superfamily $\mathrm{F}$ [C. magus] & QFQ60999.1 & & & \\
\hline $\mathrm{H}$ & SLVYVNLKK & Conotoxin precursor superfamily $\mathrm{H}$ [C. ermineus] & AXL95408.1 & 1 & Unknown & Unknown \\
\hline \multirow{3}{*}{11} & $\begin{array}{l}\text { MKLALTFLLILMILPLTTGGK } \\
\text { MKLALTFLLILMILPLTTGGKK }\end{array}$ & Conotoxin Im11.13 [C. imprialis] & ADZ74137.1 & & \multirow{3}{*}{$\begin{array}{l}\mathrm{Na}^{+} \text {channels } \\
\text { activator }\end{array}$} & \multirow{3}{*}{$\begin{array}{l}\text { Treatment } \\
\text { of heart } \\
\text { failures } \\
\text { and pain }\end{array}$} \\
\hline & FQKTVPNKCAGDIEI & Contoxin M11.2 [C. magus] & P0C613.1 & 3 & & \\
\hline & EDSLNCIETMATTATCMKSNK & $\begin{array}{l}\text { G115_VD_Superfamily_I1_precursor_conopeptide } \\
\text { [C. geographus] }\end{array}$ & BAO65648.1 & & & \\
\hline \multirow{3}{*}{12} & LSLASSAVLMLLLLFALGNFVGVQPGQITR & Conotoxin Im9.12 [C. imprialis] & ADZ99328.1 & \multirow{3}{*}{3} & \multirow{3}{*}{$\mathrm{K}^{+}$channels } & \multirow{3}{*}{$\begin{array}{c}\text { Treatment } \\
\text { of neuronal } \\
\text { disorder } \\
\text { diseases } \\
\text { and cancer }\end{array}$} \\
\hline & SLNECAVR & Conotoxin Sx11.2 [C. striolatus] & P0C258.1 & & & \\
\hline & NEEDHLRLISMQKGGNLK & Conotoxin Gla-TxX [C. textile] & Q514E6.1 & & & \\
\hline
\end{tabular}


Table 1. Cont.

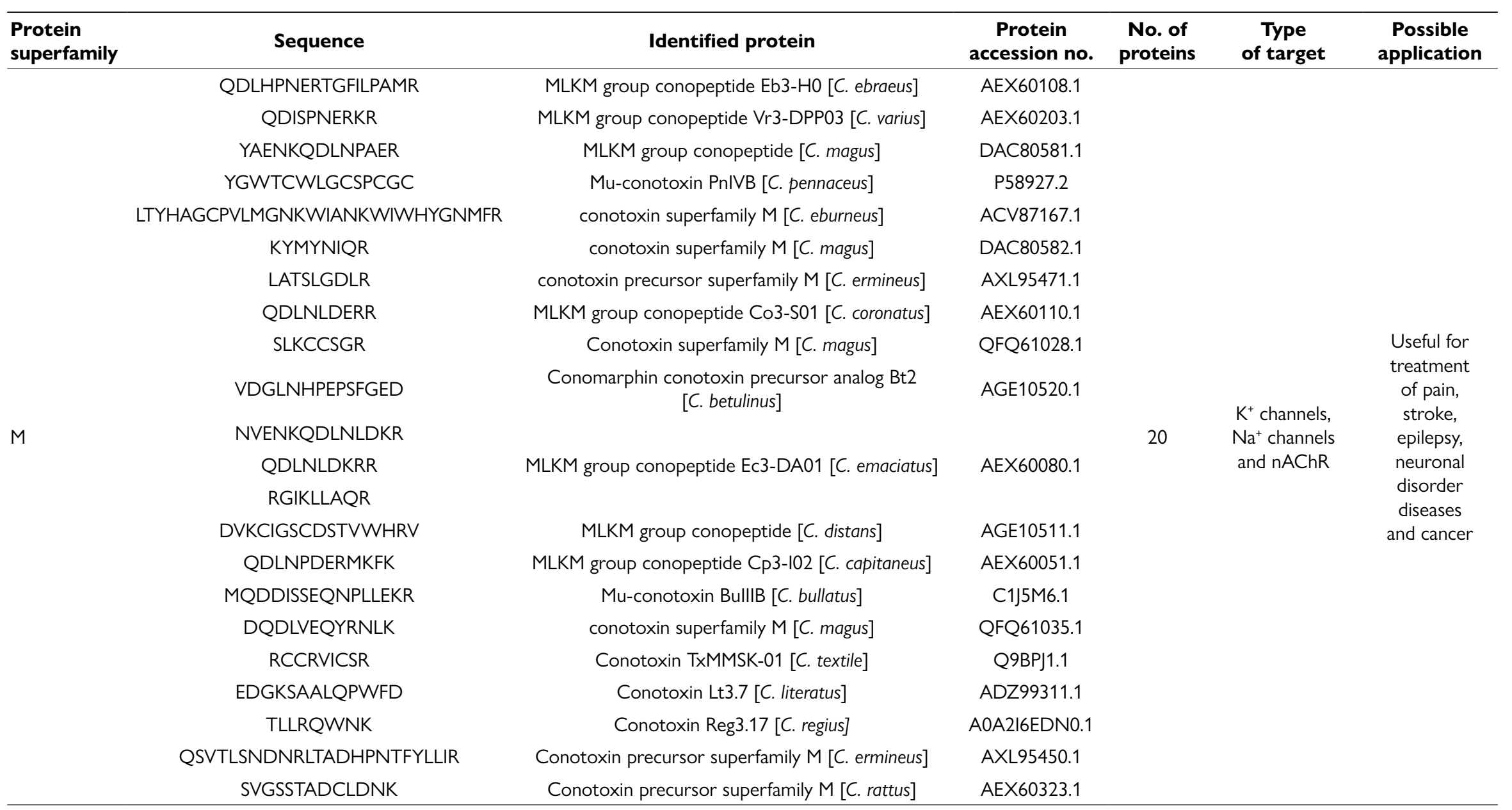




\begin{tabular}{|c|c|c|c|c|c|c|}
\hline $\begin{array}{l}\text { Protein } \\
\text { superfamily }\end{array}$ & Sequence & Identified protein & $\begin{array}{c}\text { Protein } \\
\text { accession no. }\end{array}$ & $\begin{array}{c}\text { No. of } \\
\text { proteins }\end{array}$ & $\begin{array}{c}\text { Type } \\
\text { of target }\end{array}$ & $\begin{array}{c}\text { Possible } \\
\text { application }\end{array}$ \\
\hline \multirow{29}{*}{ O1 } & LTCMMIVAVLSLTAWTFATADDPR & Conotoxin precursor superfamily O1 [C. episcopatus] & BAS22635.1 & \multirow{29}{*}{27} & \multirow{29}{*}{$\begin{array}{l}\mathrm{Ca}^{+} \text {channels, } \\
\mathrm{K}^{+} \text {channels, } \\
\mathrm{Na}^{+} \text {channels } \\
\text { and nAChR }\end{array}$} & \multirow{29}{*}{$\begin{array}{c}\text { Useful in } \\
\text { pain, stroke, } \\
\text { hypertension, } \\
\text { arrhythmias, } \\
\text { epilepsy, } \\
\text { neuronal } \\
\text { disorder } \\
\text { diseases } \\
\text { and cancer }\end{array}$} \\
\hline & FDNDCCDACMLREKQQPICAV & Conotoxin precursor superfamily $\mathrm{O} 1$ [C. miles] & Q3YEG3.1 & & & \\
\hline & TASKLLQGSQVAASPL & Conotoxin precursor superfamily $\mathrm{O} 1$ [C. ermineus] & AXL95342.1 & & & \\
\hline & NELENLFPKARHEMD & Conetoxin nrecursor cunerfamily 01 [C ermineucl & $A \times 1953531$ & & & \\
\hline & NELESYAYSLKNQVNDKEK & 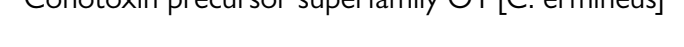 & HALMJJJ. & & & \\
\hline & KCLGFGEACLMFYSDCCSFCVRAVCL & Conotoxin precursor superfamily $\mathrm{O} 1$ [C. episcopatus] & BAS22577.1 & & & \\
\hline & GKGAPCRK & Conotoxin precursor superfamily $\mathrm{O} 1$ [C. magus] & 1OMN_A & & & \\
\hline & NGLGNLFSNAHHEMK & Conotoxin precursor superfamily $\mathrm{O} 1 \mathrm{C}$. episcopatus] & BAS22395.1 & & & \\
\hline & MKNPEASKLNNR & Conotoxin precursor superfamily $\mathrm{O} 1 \mathrm{C}$. episcopatus] & BAS22442.1 & & & \\
\hline & QVYRAVGLTDKMR & Conotoxin precursor superfamily $\mathrm{O} 1$ [C. magus] & QFQ61065.1 & & & \\
\hline & ARNELQKLEASQLNER & Conotoxin precursor superfamily $\mathrm{O} 1$ [C. virgo] & Q3YED8.1 & & & \\
\hline & DKQEHPAVRGSDDMQDSEDLK & Conotoxin precursor superfamily $\mathrm{O} 1$ [C. arenatus] & Q9BP77.1 & & & \\
\hline & SHNCCGVCMIRKLPK & Conotoxin precursor superfamily $\mathrm{O} 1$ [C. ermineus] & AXL95510.1 & & & \\
\hline & ALMSTGTNYRLLK & Conotoxin GeXXXIA [C. generalis] & A0A2I4QAG8.1 & & & \\
\hline & NIDGREASGLRK & Conotoxin precursor superfamily $\mathrm{O} 1$ [C. ermineus] & AXL95529.1 & & & \\
\hline & RYYTCVALS & Conotoxin nrecursor sunerfamily 01 [C ebiscobatus] & BAS225841 & & & \\
\hline & YYTCVALS & & & & & \\
\hline & MLSMLAWTLMTAMVVMNA & Conotoxin precursor superfamily $\mathrm{O} 1$ [C. episcopatus] & BAS22670.1 & & & \\
\hline & CIVGTPCHVCRSQSKSCNGWLGK & Conotoxin Bu6 [C. bullatus] & P0CY65.1 & & & \\
\hline & LEKRDCQDK & Conotoxin Tx6.6 [C. textile] & P0DPM4.1 & & & \\
\hline & GLGYLTFCPSNLGTTLR & Conotoxin precursor superfamily $\mathrm{O} 1$ [C. episcopatus] & BAS22548.1 & & & \\
\hline & LDFGDLDPKNE & Conotoxin precursor superfamily $\mathrm{O} 1$ [C. ermineus] & AXL95735.1 & & & \\
\hline & CKSPGTPCSKGMR & Conotoxin precursor superfamily $\mathrm{O} 1$ [C. geographus] & BAO65621.1 & & & \\
\hline & VGTGLGEYMFDK & Conotoxin ArMKLT1-02 [C. arenatus] & Q9BP99.1 & & & \\
\hline & MLSMLAWTLMTAMVVMNA & Conotoxin precursor superfamily $\mathrm{O} 1$ [C. episcopatus] & BAS22670.1 & & & \\
\hline & LNHPEPDFGDLSKLGFGNLDPGG & Conotoxin precursor superfamily $\mathrm{O} 1$ [C. episcopatus] & BAS22556.1 & & & \\
\hline & LSATPGFKD & Conotoxin precursor superfamily $\mathrm{O} 1$ [C. episcopatus] & BAS22677.1 & & & \\
\hline & NLLKIGTRGQGGCVPPGGGR & Conotoxin precursor superfamily $\mathrm{O} 1$ [C. geographus] & BAO65614.1 & & & \\
\hline & MTKRCMHPEGGCR & Conotoxin AbVIE [C. abbreviates] & Q9UA85.1 & & & \\
\hline
\end{tabular}




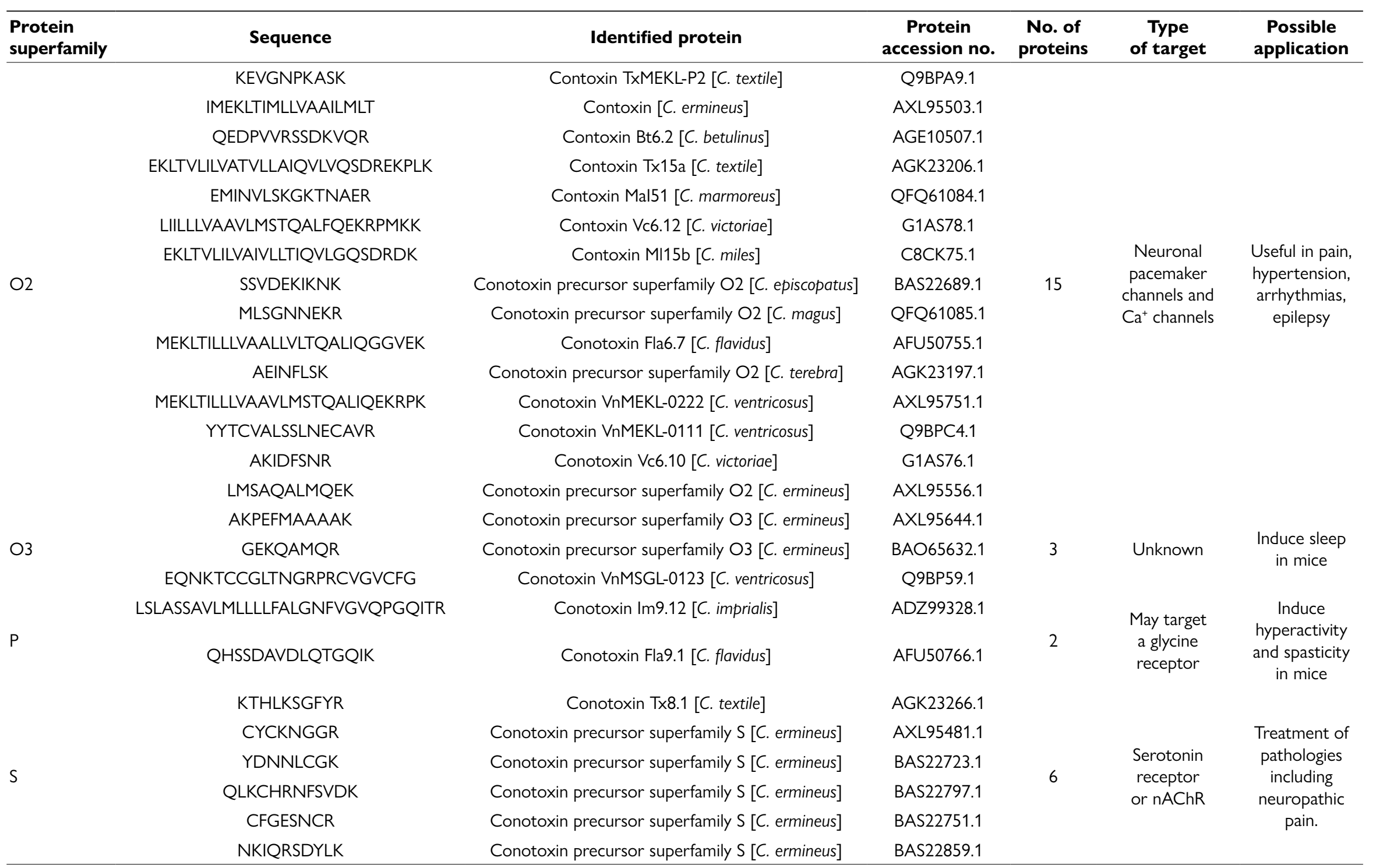




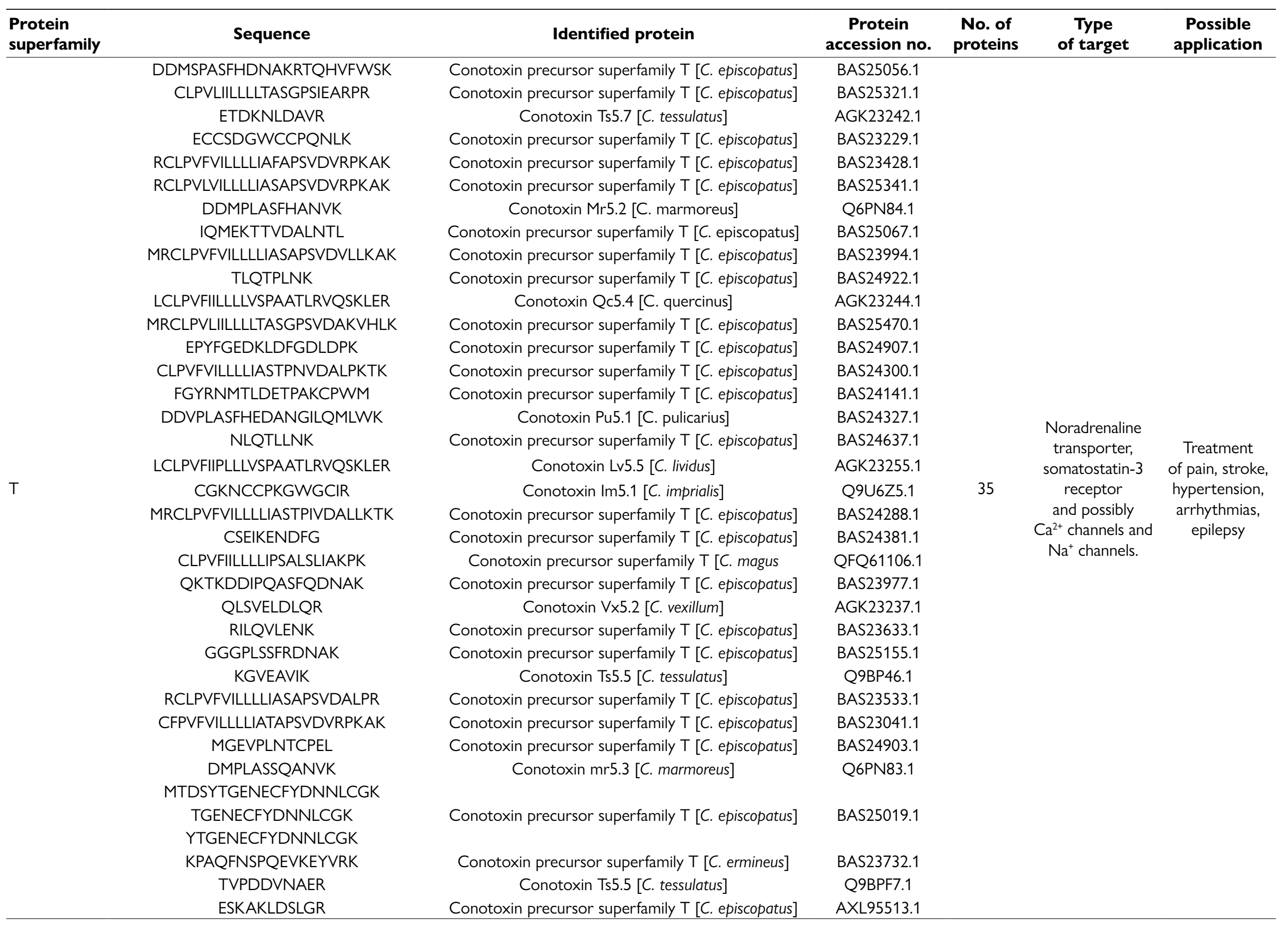


Table 1. Cont.

\begin{tabular}{|c|c|c|c|c|c|c|}
\hline $\begin{array}{l}\text { Protein } \\
\text { superfamily }\end{array}$ & Sequence & Identified protein & $\begin{array}{c}\text { Protein } \\
\text { accession no. }\end{array}$ & $\begin{array}{c}\text { No. of } \\
\text { proteins }\end{array}$ & $\begin{array}{c}\text { Type } \\
\text { of target }\end{array}$ & $\begin{array}{c}\text { Possible } \\
\text { application }\end{array}$ \\
\hline \multirow{2}{*}{$\vee$} & SDPPVSLVKVDCTAETK & Conotoxin Vi15a [C. virgo] & B3FIA5.1 & \multirow{2}{*}{2} & \multirow{2}{*}{ Unknown } & \multirow{2}{*}{ Unknown } \\
\hline & LGLTEFEAIQEMR & Conotoxin Fla15.3 [C. flavidus] & AFU50801.1 & & & \\
\hline Con-ikot-ikot & SDVERALNIEIRR & Con-ikot-ikot [C. magus] & QFQ60982.1 & 1 & $\begin{array}{c}\text { a-amino-3- } \\
\text { hydroxy-5- } \\
\text { methyl-4- } \\
\text { isoxazole } \\
\text { propionic } \\
\text { acid (AMPA) } \\
\text { receptors }\end{array}$ & $\begin{array}{c}\text { Inhibiting } \\
\text { channel } \\
\text { desensitization }\end{array}$ \\
\hline \multirow{4}{*}{ Conkunitzin } & LEPDAGLCR & Conkunitzin [C. ermineus] & AXL95648.1 & & & \multirow{4}{*}{$\begin{array}{l}\text { Neuronal } \\
\text { disorder } \\
\text { diseases } \\
\text { and cancer }\end{array}$} \\
\hline & ISMQKGGNLK & Conkunitzin [C. magus] & DAC80559.1 & 3 & $\mathrm{~K}^{+}$channels & \\
\hline & SMQKGGNLK & & & & & \\
\hline & RMGEVPLNTCPELFE & Conkunitzin [C. ermineus] & AXL95589.1 & & & \\
\hline \multirow{4}{*}{ Conodipin } & HFLAACDR & Conodipin [C. magus] & DAC80618.1 & \multirow{4}{*}{4} & \multirow{4}{*}{$\begin{array}{l}\text { Conotoxin with } \\
\text { PLA }_{2} \text { activity. }\end{array}$} & \multirow{4}{*}{$\begin{array}{c}\text { Potent } \\
\text { neurotoxicity, } \\
\text { Neurologic } \\
\text { application for } \\
\text { pain reduction }\end{array}$} \\
\hline & QVASDRATSIAR & Conodipin [C. purpurascens] & QEO32927.1 & & & \\
\hline & LISMQMGGNLK & Conodipin [C. buxeus loroisii] & ATJ04131.1 & & & \\
\hline & ACFIRNCPK & Conodipin [C. ermineus] & AXL95508.1 & & & \\
\hline \multirow{5}{*}{ Cerm } & CSTDSDHTITVVQSYINGYPEKR & & & \multirow{5}{*}{2} & \multirow{5}{*}{ Unknown } & \multirow{5}{*}{ Unknown } \\
\hline & QVCPTMTDSYTGENECFYDNNLCGK & Cerm-13 [Pionoconus magus] & QFQ61140.1 & & & \\
\hline & CVALSSLNECAVR & & & & & \\
\hline & CSSRCYCKNGGR & & & & & \\
\hline & LTPDKVEMATLTR & Cerm-18 [C. ermineus] & AXL95455.1 & & & \\
\hline \multirow{4}{*}{$\begin{array}{l}\text { Conopressin/ } \\
\text { Conophysin }\end{array}$} & RATKECMYCSLGQCVGPR & Cononressin/Cononbvsin [C ermineus] & $A \times 1955081$ & \multirow{4}{*}{2} & \multirow{4}{*}{\multicolumn{2}{|c|}{$\begin{array}{l}\text { Antidiuresis, } \\
\text { stimulation } \\
\text { of liver } \\
\text { glycogenolysis, } \\
\text { and central } \\
\text { regulation } \\
\text { of somatic } \\
\text { functions }\end{array}$}} \\
\hline & ACFIRNCPK & & & & & \\
\hline & & & & & & \\
\hline & DPISVKVLCR & Conopressin/Conophysin [C. magus] & DAC80606.1 & & & \\
\hline Prohrmone-4 & YALRLATSLGDLRWSLALTDENINNTK & hormone superfamily prohormone-4 & DAC80609.1 & 1 & Unknown & Unknown \\
\hline Pmag & QVALGLEEGWR & Pmag295 ferritin [C. magus] & AXL95451.1 & 1 & Iron receptor & Unknown \\
\hline Total & 170 & & & 153 & & \\
\hline
\end{tabular}


Table 2. List of non-conotoxin proteins identified in Egyptian C. taeniatus venom by using MALDI/TOF/MS.

\begin{tabular}{|c|c|c|c|c|c|}
\hline $\begin{array}{l}\text { Protein } \\
\text { family }\end{array}$ & Sequence & Identified protein & $\begin{array}{c}\text { Protein } \\
\text { accession no. }\end{array}$ & $\begin{array}{c}\text { No. of } \\
\text { proteins }\end{array}$ & $\begin{array}{l}\text { Biological } \\
\text { process }\end{array}$ \\
\hline \multirow{12}{*}{ Conoporin } & VSCIIQVENWTR & Cononorin [C lividuc] & $\Delta T C 050401$ & \multirow{12}{*}{8} & \multirow{12}{*}{$\begin{array}{l}\text { Punching Holes } \\
\text { in Membranes. } \\
\text { Osmotic stress } \\
\text { and cell death of } \\
\text { microorganisms }\end{array}$} \\
\hline & LVASEVVTPG & Conoporm [C. IVIVUS] & AIG85040.1 & & \\
\hline & AEGAMTNGNHAQVK & & & & \\
\hline & VIVRPTRNNWK & Conoporin [C. ebraeus] & ASF90529.1 & & \\
\hline & YSNWMGLGMTR & & 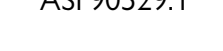 & & \\
\hline & VQVENWTRYPLMTPR & & & & \\
\hline & GKREAFAVR & Conoporin [C. magus] & DAC80623.1 & & \\
\hline & LQTIYAKDK & Conoporin [C. consors] & P0DKQ8.1 & & \\
\hline & EAFAVQMPSSGR & Conoporin [C. ermineus] & AXL95502.1 & & \\
\hline & RFVLMWSAPFDFN & Conoporin [C. lividus] & ATG85040.1 & & \\
\hline & LGLTEFEAIQEMR & Conoporin [C. monile] & ANC48005.1 & & \\
\hline & ALQQKRSLQR & Conoporin [C. magus] & QFQ61164.1 & & \\
\hline \multirow{14}{*}{$\begin{array}{l}\text { Protein } \\
\text { disulfide } \\
\text { isomerase }\end{array}$} & TFIDSDEVIVMGFFKDQEGKGA & Protein disulfide isomerase [C. ebraeus] & ASF90532.1 & \multirow{14}{*}{27} & \multirow{14}{*}{$\begin{array}{l}\text { Oxidative folding } \\
\text { of conopeptides }\end{array}$} \\
\hline & VLFIYLDTAKT & & & & \\
\hline & EDVVFGITSEDSVFKEHK & Protein disulfide isomerase [C.geographus] & AMM62652.1 & & \\
\hline & GKVLFIYLDTAKEENEHI & Protein disulfide isomerase $[C$. ermineus $]$ & AXL95726.1 & & \\
\hline & ADSPAMRLIQLGEDLAK & Protein disulfide isomerase [C. magus] & QFQ61177.1 & & \\
\hline & LFIYLDTAKEESEHIMGFFGLKAADAPTMR & Protein disulfide isomerase [C lividus] & ATG85035.1 & & \\
\hline & TENFDKFIK & & & & \\
\hline & FFMNGQSVDYTGGRQ & Protein disulfide isomerase [C. bullatus] & AMM62658.1 & & \\
\hline & GSNIKLAKVDATVEK & Protein disulfide isomerase [C. ermineus] & AXL95393.1 & & \\
\hline & LAKVDIIAEMD & Protein disulfide isomerase [C aenorahhus] & AMM626501 & & \\
\hline & LAKVDIIAEM & 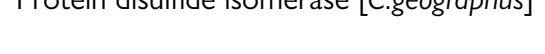 & Aा ता 102050.1 & & \\
\hline & QLAPQYSAAA & Protein disulfide isomerase [C. literatus] & ARS01447.1 & & \\
\hline & TVETDLAGKFEVK & \multirow{2}{*}{ Protein disulfide isomerase [C. magus] } & \multirow{2}{*}{ DAC80628.1 } & & \\
\hline & TAQKIFAGDIQNH & & & & \\
\hline
\end{tabular}




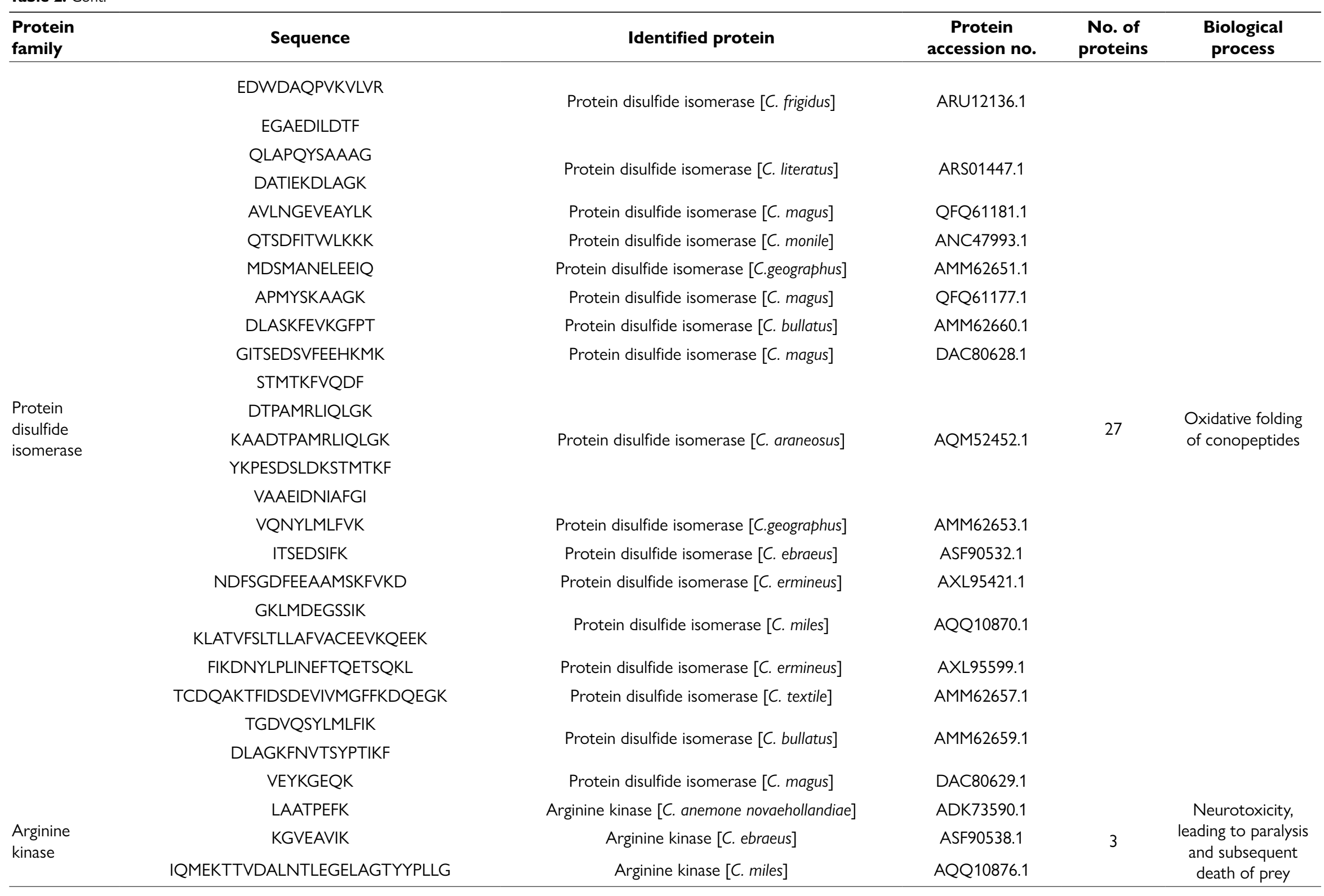


Table 2. Cont

\begin{tabular}{|c|c|c|c|c|c|}
\hline $\begin{array}{l}\text { Protein } \\
\text { family }\end{array}$ & Sequence & Identified protein & $\begin{array}{c}\text { Protein } \\
\text { accession no. }\end{array}$ & $\begin{array}{c}\text { No. of } \\
\text { proteins }\end{array}$ & $\begin{array}{l}\text { Biological } \\
\text { process }\end{array}$ \\
\hline \multirow{3}{*}{$\begin{array}{l}\text { ATP synthase } \\
\text { F0 subunit } 8\end{array}$} & VMFSGKGLDCADLK & ATP synthase F0 subunit 8 [C. betulinus] & YP_009538431.1 & \multirow{3}{*}{3} & \multirow{3}{*}{$\begin{array}{l}\text { Important enzyme } \\
\text { that provides } \\
\text { energy to be } \\
\text { used by the cell } \\
\text { through the } \\
\text { synthesis of ATP }\end{array}$} \\
\hline & IMFSSKSLTYINLGKENK & ATP synthase F0 subunit 8 [C. iosephinae] & ATZ70391.1 & & \\
\hline & KIMFSSKSSTYTNLSK & ATP synthase F0 subunit $8[C$. borgesi $]$ & YP_003204749.1 & & \\
\hline $\begin{array}{l}\text { Kazal } \\
\text { protease } \\
\text { inhibitor }\end{array}$ & CAGDIEICK & Kazal protease inhibitor [C. ermineus] & AXL95542.1 & 1 & $\begin{array}{l}\text { Inhibits } \\
\text { serine proteases, } \\
\text { including trypsin, } \\
\text { chymotrypsin, } \\
\text { and elastase. }\end{array}$ \\
\hline \multirow{6}{*}{$\begin{array}{l}\text { NADH } \\
\text { dehydrogenase } \\
\text { subunits }\end{array}$} & NNSSEVDIIMSK & NADH dehydrogenase subunits [C. pseudonivifer] & ATZ70266.1 & \multirow{6}{*}{6} & \multirow{6}{*}{$\begin{array}{l}\text { Mitochondrial } \\
\text { membrane } \\
\text { respiratory }\end{array}$} \\
\hline & ELFVLFCVMSGGSALIGGMGGLNQTQVR & NADH dehydrogenase subunits [C. (Lautoconus) sp] & ATZ70968.1 & & \\
\hline & SIVVMISMLNVVGSVLILLSNFAEGM & NADH dehydrogenase subunits [C. geographus] & ATZ70864.1 & & \\
\hline & LGILLANFLILVIFPLAGK & NADH dehydrogenase subunits [C. venulatus] & APH08616.1 & & \\
\hline & MLGILLANFLILVILPLISKKWSWYLK & NADH dehydrogenase subunits [C. trochulus] & ATZ69913.1 & & \\
\hline & ETSKPASQLILN & NADH dehydrogenase subunits [C. borgesi] & YP_003204755.1 & & \\
\hline Total & 64 & & & 48 & \\
\hline
\end{tabular}


produce diverse conopeptides. Low molecular weight peptides in venom specifically alter $\mathrm{Na}^{+}, \mathrm{Ca}^{2+}, \mathrm{K}^{+}$, and $\mathrm{Cl}^{-}$ion channels $[38,39]$. Because these low molecular weight peptides have the ability to block voltage-gated channels, they can be employed in tumor growth impairment $[40,41]$. Therefore, the discovered low molecular weight peptides in C. taeniatus and other Conus venoms could be employed in tumor treatment because they can most likely control the signal transduction pathways in malignant tumor cells.

Peptide toxins are usually highly bridged proteins with multiple pairs of intrachain disulfide bonds. The analysis of disulfide connectivity is important in protein structure determination [42]. The disulfide pattern in the venom peptides of $C$. taeniatus was estimated directly by LCMS-IT-TOF without venom fractionation. We reported herein that most $C$. taeniatus peptides were disulfiderich, with the highest possibility of 3 disulfide bridges. Disulfiderich peptides were also abundant in the venom of $C$. consors [43], C. bandanus and C. marmoreus [2] and C. fulgetrum [37]. It is well known that disulfide bonds confer conformational stability to folded proteins [44]. Therefore, an understanding of disulfide linkage patterns is necessary for further studies relating the structure to the function of Conus venom peptides.

Classical peptide identification methods, including Sanger sequencing and isolation, are generally considered laborious with limited efficiency and are sometimes limited by sample availability. The advance of high-throughput sequencing combined with bioinformatics analysis has allowed for more precise identification of conopeptides to predict and discover novel conotoxins from a variety of Conus species [34,45-49]. Here, the majority of conotoxins identified in C. taeniatus belonged to the T-superfamily, suggesting an important function for C. taeniatus. The T-superfamily peptides in Conus venom target different types of ion channels or neurotransmitters [50,51]. Similarly, the T-superfamily is predominant in C. victoriae venom [52]. Evidently, the T-superfamily is abundant in C. taeniatus and other Conus species; however, little is known about this group of conotoxins. Variations in conotoxin targets enable them to be included in the treatment of several diseases, such as pain, cancers and depression $[1,53,54]$. For example, M-superfamily peptides, which are ubiquitous in Conus venom [55], are blockers of voltage-gated sodium and potassium channels or nicotinic acetylcholine receptors. Conopeptides from the $\mathrm{O}$-superfamily, which have $\mathrm{O} 1, \mathrm{O} 2$, and $\mathrm{O} 3$ variations, can block voltage-gated calcium and potassium channels $[56,57]$. Currently, ziconotide from the $\mathrm{O} 1$ superfamily is commercially available and works as an analgesic that relieves pain by selectively inhibiting the $\mathrm{N}$-type voltage-gated $\mathrm{Ca}^{++}$channel, and thus inhibiting the release of pro-nociceptive neurochemicals in the spinal cord $[58,59]$. The $\mathrm{M}$ - and $\mathrm{O}$-superfamilies are the predominant superfamilies in C. tribblei, C. bullatus, C. marmoreus, and C. pulicarius [52]. Additionally, A-superfamily conopeptides are the most abundant in C. consors, C. geographus, and C. bullatus [52], and together with the O-superfamilies, can block potassium channels and affect nicotinic acetylcholine receptors [32,60].
As conopeptides in C. taeniatus can target different ion channels and receptors, they are promising candidate compounds for biomedical applications and drug development.

In addition to conopeptides, different non-conopeptide proteins and enzymes were detected. Conoporin, which is known as a potent cytolytic and hemolytic protein, was detected in $C$. taeniatus venom. Conoporins exert toxicity by forming pores in membranes, leading to cell death [61]. Interestingly, different peptide fragments of conoporins were identified, indicating the potential antimicrobial activity of $C$. taeniatus venom. The enzyme family protein disulfide-isomerase (PDI) was detected in the venom of $C$. taniatus and can catalyze the oxidation, isomerization, and reduction of disulfide bonds to ensure the proper folding of proteins. PDI confers stability to proteins by covalently linking specific cysteine residues $[53,62]$. This enzyme family has also been identified in the venom glands of several insects, including Aphidius ervi [63] and Psytallia species [64], and in the crude venom extract of Pteromalus puparum [65], Diversinervus elegans [66] and Cotesia chilonis [67]. In venomous cone snails, PDIs are only located in the venom glands directing the folding of conotoxins but not in the secreted venom $[68,69]$. PDIs rarely exist in the extracellular space and are principally localized in the endoplasmic reticulum [70]. Therefore, the presence of PDI in the extracted venom of $C$. taeniatus is probably due to the rupture of venom-producing cells during venom collection. In this study, several of the detected protein fragments could not be attributed to conopeptides. One possible explanation is that the extracted venom may contain other untreated peptides and cellular debris. In addition, whole conotoxin sequences are not described and available in the database.

\section{Conclusion}

The data described herein contribute to addressing the gap of knowledge regarding the venom composition of the neglected vermivore cone snail C. taeniatus at the proteomic level. We used different proteomic approaches to characterize various peptide compositions of $C$. taeniatus venom. We successfully identified 170 out of 234 peptide fragments and classified them into 23 known gene superfamilies. Many conopeptide superfamilies targeting various types of ion channels and receptors were identified in the venom composition of the worm-hunting $C$. taeniatus, making them valuable lead compounds for drug development and biomedical applications. Therefore, further research with more sensitive methods are required to determine the peptide composition of untapped cone snail venoms.

\section{Abbreviations}

AA: acetic acid; DTT: dithiothreitol; ESI: electrospray ion source; FA: formic acid; HPLC: high-performance liquid chromatography; MALDI-TOF matrix-assisted laser desorption/ ionization time-of-flight; MM: Monoisotopic molecular masses; MS: mass spectrometry; PDI: disulfide-isomerase; PTM: posttranslational modifications; RP-HPLC: reversd-phase HPLC. 


\section{Acknowledgments}

The authors are grateful to the Deanship of Scientific Research at Jouf University, Saudi Arabia, for funding this work (research grant number 40/284). We are grateful to Dr. M. Miyashita, associate professor of Kyoto University, for his valuable collaboration in the preliminary experiments. The authors extend their appreciation to the proteomics and metabolomics unit at Children Cancer Hospital (CCHE-57357).

\section{Availability of data and materials}

All data generated or analyzed during this study are included in this article.

\section{Funding}

This work was supported by grants from the Deanship of Scientific Research at Jouf University, Saudi Arabia (research grant number 40/284).

\section{Competing interests}

The authors declare that they have no competing interests

\section{Authors' contributions}

MA and AM collected conus samples and performed the extraction of the venom. MMAF, MA and MS analyzed the proteomic data and wrote the manuscript. MOG supervised the data analysis. MS is the designer of the research. MMAF and MOG applied for funding. All authors read, corrected and approved the final manuscript.

\section{Ethics approval}

Not applicable

\section{Consent for publication}

Not applicable.

\section{Supplementary material}

The following online material is available for this article:

Additional file 1. Monoisotopic molecular masses (MM) of native components in Conus taeniatus venom detected by LC/ MS analysis.

Additional file 2. Monoisotopic molecular masses (MM) of reduced and alkylated components in Conus taeniatus venom detected by LC/MS analysis.

Additional file 3. Estimation of the number of disulfide bridges included in each component in Conus taeniatus venom.

Additional file 4. List of peptide sequences detected in $C$. taeniatus venom by using MALDI/TOF/MS.

\section{References}

1. Lewis RJ, Dutertre S, Vetter I, Christie MJ. Conus venom peptide pharmacology. Pharmacol Rev. 2012 Apr;64(2):259-98.

2. Nguyen B, Molgó J, Lamthanh H, Benoit E, Khuc TA, Ngo DN, Nguyen NT, Millares P, Le Caer JP. High accuracy mass spectrometry comparison of Conus bandanus and Conus marmoreus venoms from the South Central Coast of Vietnam. Toxicon. 2013;75:148-59.

3. Röckel D, Korn W, Kohn AJ. Manual of the living Conidae. Vol. 1, IndoPacific Region. Wiesbaden: Verlag Christa Hemmen; 1995.

4. Olivera BM. E.E. Just Lecture, 1996. Conus venom peptides, receptor and ion channel targets, and drug design: 50 million years of neuropharmacology. Mol Biol Cell. 1997 Nov;8(11):2101-9.

5. Favreau P, Stöcklin R. Marine snail venoms: use and trends in receptor and channel neuropharmacology. Curr Opin Pharmacol. 2009 Oct;9(5):594-601.

6. Lewis RJ, Garcia ML. Therapeutic potential of venom peptides. Nat Rev Drug Discov. 2003 Oct;2(10):790-802.

7. Terlau H, Olivera BM. Conus venoms: a rich source of novel ion channeltargeted peptides. Physiol Rev. 2004 Jan;84(1):41-68.

8. Olivera BM. $\omega$-Conotoxin MVIIA: from marine snail venom to analgesic drug. In: Fusetani N, editor. Drugs from the Sea. Switzerland: Karger; 2000. p. 74-85.

9. Miljanich GP. Ziconotide: neuronal calcium channel blocker for treating severe chronic pain. Curr Med Chem. 2004 Dec;11(23):3029-40.

10. Bingham JP, Mitsunaga E, Bergeron ZL. Drugs from slugs - past, present and future perspectives of omega-conotoxin research. Chem Biol Interact. 2010 Jan 5;183(1):1-18.

11. Pennington MW, Czerwinski A, Norton RS. Peptide therapeutics from venom: current status and potential. Bioorg Med Chem. 2018 Jun1;26(10):2738-58.

12. Brinzeu A, Berthiller J, Caillet JB, Staquet H, Mertens P. Ziconotide for spinal cord injury-related pain. Eur J Pain. 2019 Oct;23(9):1688-700.

13. King GF. Venoms as a platform for human drugs: translating toxins into therapeutics. Expert Opin Biol Ther. 2011 Nov;11(11):1469-84.

14. Davis J, Jones A, Lewis RJ. Remarkable inter- and intra-species complexity of conotoxins revealed by LC/MS. Peptides. 2009 Jul;30(7):1222-7.

15. Espiritu DJ, Watkins M, Dia-Monje V, Cartier GE, Cruz LJ, Olivera BM. Venomous cone snails: molecular phylogeny and the generation of toxin diversity. Toxicon. 2001 Dec;39(12):1899-916.

16. Rodriguez AM, Dutertre S, Lewis RJ, Marí F. Intraspecific variations in Conus purpurascens injected venom using LC/MALDI-TOF-MS and LC-ESI-TripleTOF-MS. Anal Bioanal Chem. 2015 Aug;407(20):6105-16.

17. Puillandre N, Bouchet P, Duda Jr TF, Kauferstein S, Kohn AJ, Olivera BM, Watkins M, Meyer C. Molecular phylogeny and evolution of the cone snails (Gastropoda, Conoidea). Mol Phylogenet Evol. 2014 Sep;78:290-303.

18. Kaas Q, Yu R, Jin AH, Dutertre S, Craik DJ. ConoServer: updated content, knowledge, and discovery tools in the conopeptide database. Nucleic Acids Res. 2012 Jan 1;40(D1):D325-30.

19. Lu A, Yang L, Xu S, Wang C. Various conotoxin diversifications revealed by a venomic study of Conus flavidus. Mol Cell Proteomics. 2014 Jan;13(1):105-18.

20. Duda Jr TF, Palumbi SR. Molecular genetics of ecological diversification: duplication and rapid evolution of toxin genes of the venomous gastropod Conus. Proc Natl Acad Sci U S A. 1999 Jun 8;96(12):6820-3.

21. Conticello SG, Gilad Y, Avidan N, Ben-Asher E, Levy Z, Fainzilber M. Mechanisms for evolving hypervariability: the case of conopeptides. Mol Biol Evol. 2001 Feb;18(2):120-31.

22. Kaas Q, Westermann JC, Halai R, Wang CKL, Craik DJ. ConoServer, a database for conopeptide sequences and structures. Bioinformatics. 2008 Feb 1;24(3):445-6.

23. Norton RS, Olivera BM. Conotoxins down under. Toxicon. 2006 Dec 1;48(7):780-98.

24. Aguilar MB, López-Vera E, Imperial JS, Falcón A, Olivera BM, Heimer de la Cotera EP. Putative $\gamma$-conotoxins in vermivorous cone snails: the case of Conus delessertii. Peptides. 2005 Jan;26(1):23-7. 
25. Loughnan M, Nicke A, Jones A, Schroeder Cl, Nevin ST, Adams DJ, Alewood PF, Lewis RJ. Identification of a novel class of nicotinic receptor antagonists: dimeric conotoxins $\mathrm{V} \times \mathrm{XIIA}, \mathrm{V} \times \mathrm{XIIB}$, and $\mathrm{V} \times \mathrm{X} I I \mathrm{C}$ from Conus vexillum. J Biol Chem. 2006 Aug 25;281(34):24745-55.

26. Zugasti-Cruz A, Maillo M, López-Vera E, Falcón A, Heimer de la Cotera EP, Olivera BM, Aguilar MB. Amino acid sequence and biological activity of a $\gamma$-conotoxin-like peptide from the worm-hunting snail Conus austini. Peptides. 2006 Mar;27(3):506-11.

27. Romeo C, Di Francesco L, Oliverio M, Palazzo P, Massilia GR, Ascenzi $P$, Polticelli $F$, Schininà ME. Conus ventricosus venom peptides profiling by HPLC-MS: a new insight in the intraspecific variation. J Sep Sci. 2008 Feb;31(3):488-98.

28. Abdel-Rahman MA, Abdel-Nabi IM, El-Naggar MS, Abbas OA, Strong PN. Conus vexillum venom induces oxidative stress in Ehrlich's ascites carcinoma cells: an insight into the mechanism of induction. J Venom Anim Toxins incl Trop Dis. 2013 May 1;19(1):10.

29. Favreau P, Menin L, Michalet S, Perret F, Cheneval O, Stöcklin M, Bulet $P$, Stöcklin R. Mass spectrometry strategies for venom mapping and peptide sequencing from crude venoms: case applications with single arthropod specimen. Toxicon. 2006 May;47(6):676-87.

30. Jones A, Bingham JP, Gehrmann J, Bond T, Loughnan M, Atkins A, Lewis $\mathrm{RJ}$, Alewood PF. Isolation and characterization of conopeptides by highperformance liquid chromatography combined with mass spectrometry and tandem mass spectrometry. Rapid Commun Mass Spectrom. 1996;10(1):138-43.

31. Abdel-Rahman MA, Abdel-Nabi IM, El-Naggar MS, Abbas OA, Strong $\mathrm{PN}$. Intraspecific variation in the venom of the vermivorous cone snail Conus vexillum. Comp Biochem Physiol C Toxicol Pharmacol. 2011 Nov;154(4):318-25.

32. Neves J, Campos A, Osório H, Antunes A, Vasconcelos V. Conopeptides from Cape Verde Conus crotchii. Mar Drugs. 2013 Jun 19;11(6):2203-15.

33. Biass D, Dutertre S, Gerbault A, Menou JL, Offord R, Favreau P, Stöcklin R. Comparative proteomic study of the venom of the piscivorous cone snail Conus consors. J Proteomics. 2009 Mar 6 [cited 2020 Nov 25];72(2):210-8.

34. Dutertre S, Jin AH, Kaas Q, Jones A, Alewood PF, Lewis RJ. Deep venomics reveals the mechanism for expanded peptide diversity in cone snail venom. Mol Cell Proteomics. 2013 Feb;12(2):312-29.

35. Batista CVF, del Pozo L, Zamudio FZ, Contreras S, Becerril B, Wanke E, Possani LD. Proteomics of the venom from the amazonian scorpion Tityus cambridgei and the role of prolines on mass spectrometry analysis of toxins. J Chromatogr B Analyt Technol Biomed Life Sci. 2004 Apr 15;803(1):55-66.

36. Batista CVF, Román-González SA, Salas-Castillo SP, Zamudio FZ, GómezLagunas F, Possani LD. Proteomic analysis of the venom from the scorpion Tityus stigmurus: biochemical and physiological comparison with other Tityus species. Comp Biochem Physiol C Toxicol Pharmacol. 2007 JulAug;146(1-2):147-57.

37. Abdel-Wahab M, Miyashita M, Kitanaka A, Juichi H, Sarhan M, Fouda M, Abdel-Rahman M, Saber S, Nakagawa Y. Characterization of the venom of the vermivorous cone snail Conus fulgetrum. Biosci Biotechnol Biochem. 2016 Oct;80(10):1879-82.

38. Possani LD, Merino E, Corona M, Bolivar F, Becerril B. Peptides and genes coding for scorpion toxins that affect ion-channels. Biochimie. $2000 \mathrm{Sep}-$ Oct;82(9-10):861-8.

39. Rodríguez de la Vega RC, Possani LD. Overview of scorpion toxins specific for $\mathrm{Na}+$ channels and related peptides: biodiversity, structure-function relationships and evolution. Toxicon. 2005 Dec 15;46(8):831-44.

40. Fiske JL, Fomin VP, Brown ML, Duncan RL, Sikes RA. Voltage-sensitive ion channels and cancer. Cancer Metastasis Rev. 2006 Sep;25(3):493-500.

41. Gómez-Varela D, Zwick-Wallasch E, Knötgen $H$, Sánchez A, Hettmann $T$, Ossipov D, Weseloh R, Contreras-Jurado C, Rothe M, Stühmer W, Pardo LA. Monoclonal antibody blockade of the human Eag1 potassium channel function exerts antitumor activity. Cancer Res. 2007 Aug 1;67(15):7343-9.

42. Wang W, Liu Z, Qian W, Fang Y, Liang S. Determination of disulfide bridges of spider peptide toxins: hainantoxin-III and hainantoxin-IV. J Venom Anim Toxins incl Trop Dis. 2009;15(2):268-77.

43. Violette A, Biass D, Dutertre S, Koua D, Piquemal D, Pierrat F, Stöcklin R, Favreau P. Large-scale discovery of conopeptides and conoproteins in the injectable venom of a fish-hunting cone snail using a combined proteomic and transcriptomic approach. J Proteomics. 2012 Sep 18;75(17):5215-25.
44. Wedemeyer WJ, Welker E, Narayan M, Scheraga HA. Disulfide bonds and protein folding. Biochemistry. 2000 Apr 18;39(15):4207-16.

45. Hu H, Bandyopadhyay PK, Olivera BM, Yandell M. Characterization of the Conus bullatus genome and its venom-duct transcriptome. BMC Genomics. 2011 Jan 25;12:60.

46. Hu H, Bandyopadhyay PK, Olivera BM, Yandell M. Elucidation of the molecular envenomation strategy of the cone snail Conus geographus through transcriptome sequencing of its venom duct. BMC Genomics. 2012 Jun 27;13:284.

47. Dutertre S, Jin AH, Vetter I, Hamilton B, Sunagar K, Lavergne V, Dutertre V, Fry BG, Antunes A, Venter DJ, Alewood PF, Lewis RJ. Evolution of separate predation- and defence-evoked venoms in carnivorous cone snails. Nat Commun. 2014 Mar 24;5:3521.

48. Lavergne V, Harliwong I, Jones A, Miller D, Taft RJ, Alewood PF. Optimized deep-targeted proteotranscriptomic profiling reveals unexplored Conus toxin diversity and novel cysteine frameworks. Proc Natl Acad Sci U S A. 2015 Jul 21;112(29):E3782-91.

49. Peng C, Yao G, Gao BM, Fan CX, Bian C, Wang J, Cao Y, Wen B, Zhu Y, Ruan Z, Zhao X, You X, Bai J, Li J, Lin Z, Zou S, Zhang X, Qiu Y, Chen J, Coon SL, Yang J, Chen JS, Shi Q. High-throughput identification of novel conotoxins from the chinese tubular cone snail (Conus betulinus) by multi-transcriptome sequencing. Gigascience. $2016 \mathrm{Apr}$ 14;5(1):1-14.

50. Li X, Chen W, Zhangsun D, Luo S. Diversity of conopeptides and their precursor genes of Conus litteratus. Mar Drugs. 2020 Sep;18(9):464.

51. Kumari A, Ameri S, Ravikrishna P, Dhayalan A, Kamala-Kannan S, Selvankumar T, Govarthanan M. Isolation and characterization of conotoxin protein from Conus inscriptus and its potential anticancer activity against cervical cancer (HeLa-HPV 16 Associated) cell lines. Int J Pept Res Ther. 2020 Jun;26:1051-9.

52. Barghi N, Concepcion GP, Olivera BM, Lluisma AO. High conopeptide diversity in Conus tribblei revealed through analysis of venom duct transcriptome using two high-throughput sequencing platforms. Mar Biotechnol (NY). 2015 Feb;17(1):81-98.

53. Wickenden A, Priest B, Erdemli G. Ion channel drug discovery: challenges and future directions. Future Med Chem. 2012 Apr;4(5):661-79.

54. Hurst $R$, Rollema $H$, Bertrand D. Nicotinic acetylcholine receptors: from basic science to therapeutics. Pharmacol Ther. 2013 Jan;137(1):22-54.

55. Jacob RB, McDougal OM. The M-superfamily of conotoxins: a review. Cell Mol Life Sci. 2010 Jan;67(1):17-27.

56. Heinemann $\mathrm{SH}$, Leipold E. Conotoxins of the O-superfamily affecting voltage-gated sodium channels. Cell Mol Life Sci. 2007 Jun;64(11):1329-40.

57. Robinson SD, Safavi-Hemami H, Mclntosh LD, Purcell AW, Norton RS, Papenfuss AT. Diversity of conotoxin gene superfamilies in the venomous snail, Conus victoriae. PLoS One. 2014 Feb 5;9(2):e87648.

58. Schroeder Cl, Lewis RJ. $\omega$-conotoxins GVIA, MVIIA and CVID: SAR and clinical potential. Mar Drugs. 2006;4(3):193-214.

59. McGivern JG. Ziconotide: a review of its pharmacology and use in the treatment of pain. Neuropsychiatr Dis Treat. 2007 Feb;3(1):69-85.

60. Peng C, Ye M, Wang Y, Shao X, Yuan D, Liu J, Hawrot E, Wang C, Chi C. A new subfamily of conotoxins belonging to the A-superfamily. Peptides. 2010 Nov;31(11):2009-16.

61. Alegre-Cebollada J, Oñaderra M, Gavilanes JG, del Pozo AM. Sea anemone actinoporins: the transition from a folded soluble state to a functionally active membrane-bound oligomeric pore. Curr Protein Pept Sci. 2007 Dec;8(6):558-72.

62. Noiva R. Protein disulfide isomerase: the multifunctional redox chaperone of the endoplasmic reticulum. Semin Cell Dev Biol. 1999 Oct;10(5):481-93.

63. Colinet D, Anselme C, Deleury E, Mancini D, Poulain J, Azéma-Dossat C, Belghazi M, Tares S, Pennacchio F, Poirié M, Gatti JL. Identification of the main venom protein components of Aphidius ervi, a parasitoid wasp of the aphid model Acyrthosiphon pisum. BMC Genomics. 2014 May 6;15(1):342.

64. Mathé-Hubert H, Colinet D, Deleury E, Belghazi M, Ravallec M, Poulain J, Dossat C, Poirié M, Gatti JL. Comparative venomics of Psyttalia lounsburyi and $P$. concolor, two olive fruit fly parasitoids: a hypothetical role for a GH1 $\beta$-glucosidase. Sci Rep. 2016 Oct 25;6:35873. 
65. Yan Z, Fang Q, Wang L, Liu J, Zhu Y, Wang F, Li F, Werren JH, Ye G. Insights into the venom composition and evolution of an endoparasitoid wasp by combining proteomic and transcriptomic analyses. Sci Rep. 2016 Jan 25;6:1-12.

66. Liu NY, Wang JQ, Zhang ZB, Huang JM, Zhu JY. Unraveling the venom components of an encyrtid endoparasitoid wasp Diversinervus elegans. Toxicon. 2017 Sep 15;136:15-26.

67. Teng ZW, Xiong SJ, Xu G, Gan SY, Chen X, Stanley D, Yan ZC, Ye GY, Fang $Q$. Protein discovery: combined transcriptomic and proteomic analyses of venom from the endoparasitoid Cotesia chilonis (Hymenoptera: Braconidae). Toxins (Basel). 2017 Apr 12;9(4):135.
68. Safavi-Hemami H, Li Q, Jackson RL, Song AS, Boomsma W, Bandyopadhyay PK, Gruber CW, Purcell AW, Yandell M, Olivera BM, Ellgaard L. Rapid expansion of the protein disulfide isomerase gene family facilitates the folding of venom peptides. Proc Natl Acad Sci U S A. 2016 Mar 22;113(12):3227-32.

69. Violette A, Leonardi A, Piquemal D, Terrat Y, Biass D, Dutertre S, Noguier F, Ducancel F, Stöcklin R, Križaj I, Favreau P. Recruitment of glycosyl hydrolase proteins in a cone snail venomous arsenal: further insights into biomolecular features of Conus venoms. Mar Drugs. 2012 Feb;10(2):258-80.

70. Turano C, Coppari S, Altieri F, Ferraro A. Proteins of the PDI family: unpredicted non-ER locations and functions. J Cell Physiol. 2002 Nov;193(2):154-63. 